\title{
Evaluating the Relative Impacts of Operational and Financial Factors on the Competitiveness of an Algal Biofuel Production Facility
}

Adam M. Hise ${ }^{1 *}$, Gregory W. Characklis ${ }^{1}$, Jordan Kern ${ }^{2}$, Robin Gerlach ${ }^{3}$, Sridhar

Viamajala $^{3}$, Robert D. Gardner ${ }^{4}$ Agasteswar Vadlamani ${ }^{3}$

1. Department of Environmental Science and Engineering, University of North Carolina, Chapel Hill, NC 24060, United States

2. Institute for the Environment, University of North Carolina, Chapel Hill, NC 24060, United States

3. Department of Chemical and Biological Engineering, Center for Biofilm Engineering, Montana State University, Bozeman, MT 59717, United States

4. Department of Chemical and Environmental Engineering, The University of Toledo, Toledo, OH 43606, United States

5. Department of Bioproducts and Biosystems Engineering, University of Minnesota, St. Paul, MN 55108, United States

* Corresponding author: ahise@live.unc.edu 


\section{Abstract}

Algal biofuels are becoming more economically competitive due to technological

3 advances and government subsidies offering tax benefits and lower cost financing. These

4 factors are linked, however, as the value of technical advances is affected by modeling

5 assumptions regarding the growth conditions, process design, and financing of the

6 production facility into which novel techniques are incorporated. Two such techniques,

7 related to algal growth and dewatering, are evaluated in representative operating and

8 financing scenarios using an integrated techno-economic model. Results suggest that these

9 techniques can be valuable under specified conditions, but also that investment subsidies

10 influence cost competitive facility design by incentivizing development of more capital

11 intensive facilities (e.g., favoring hydrothermal liquefaction over transesterification-based

12 facilities). Evaluating novel techniques under a variety of operational and financial

13 scenarios highlights the set of site-specific conditions in which technical advances are most

14 valuable, while also demonstrating the influence of subsidies linked to capital intensity.

15 Keywords: Algae, Biofuels, Techno-Economic Analysis, Life Cycle Analysis, Financing 


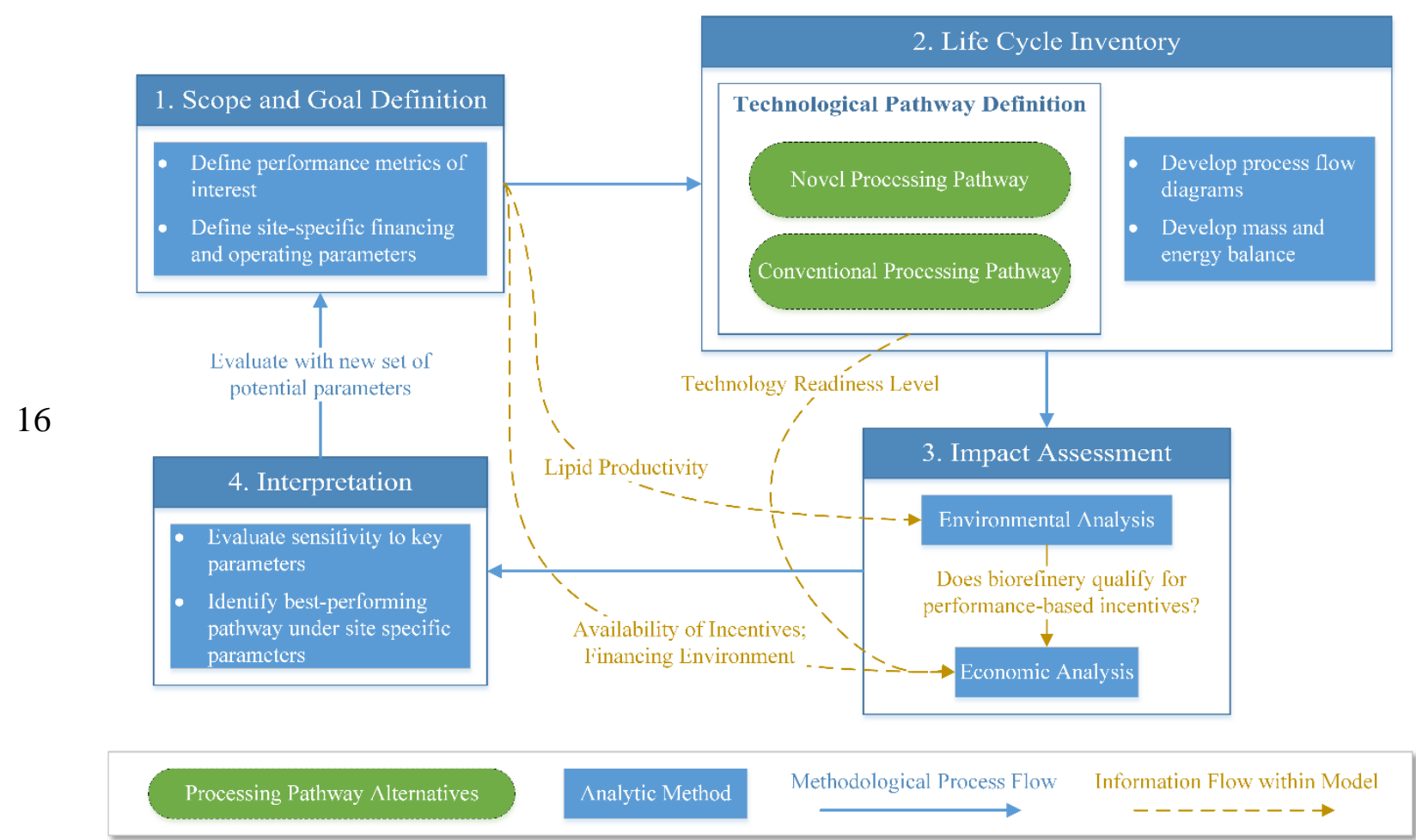

17 Graphical Abstract 
1. Introduction

Producing biofuels from microalgae offers the potential to mitigate many of the

20 challenges faced by crop-based biofuels, thanks to advantages conferred by efficient

21 microbial processes and an increasingly closed-loop production system. Microalgae can

22 produce 30 to 100 times more energy per hectare than terrestrial feedstocks (Kirrolia et al.,

23 2013) as a result of a highly efficient photosynthesis pathway (Brennan and Owende, 2010)

24 and the significant mass fraction of readily-convertible lipids in oleaginous algal strains

25 (Chisti, 2007). In contrast to agriculturally produced terrestrial biofuels feedstocks, algal

26 biofuel production can occur in a highly engineered and resource efficient biorefinery,

27 encompassing biomass cultivation, harvesting, and conversion to fuels and coproducts

28 (Rawat et al., 2013). Such processing can occur on non-arable land (further reducing

29 competition with food crops) and allows for high levels of water, nutrient, and energy

30 recycling, a necessary component for sustainable, commercial-scale algal biofuel

31 production (Chowdhury et al., 2012).

Relative to agriculturally-based $1^{\text {st }}$ and $2^{\text {nd }}$ generation biofuels production systems,

33 integrated algal biorefineries are both material and capital intensive (Collet et al., 2013).

34 The substantial upfront capital expenses for developing commercial scale facilities require

35 financing, which has been impeded by the use of processing techniques unproven at scale

36 and the commensurate uncertainty in long-term system performance (Kirrolia et al., 2013).

37 Systems analysis methodologies, especially techno-economic analysis (TEA) and life cycle

38 analysis (LCA), can be used to provide forecasts of facility economic competitiveness (Zhu

39 et al., 2013) and life cycle environmental impacts (Klöpffer, 1997), elucidating the

40 production risks and thereby barriers to investment (Miller et al., 2013). 
These methods have been widely utilized to evaluate the performance improvements achievable through incorporation of novel techniques for algal cultivation,

43 harvesting/dewatering, extraction/conversion, and recycling (Quinn and Davis, 2014).

44 Process (i.e. unit operation) decisions have systems-level (i.e. biorefinery) implications,

45 since process-specific constraints dictate input and output flow characteristics which impact

46 up- and down-stream operations (Richardson et al., 2014). The benefits of incorporating a

47 novel technique will therefore vary with the pathway in which the technique is incorporated

48 (Resurreccion et al., 2012). Uncertainty surrounding operational parameters known to

49 affect these benefits is generally not addressed in feasibility analyses, thereby limiting the

50 applicability of the associated findings. Modeled performance of algal biofuel facilities has

51 proven particularly sensitive to assumed algal growth rates (Liu et al., 2013) and lipid

52 content (Clarens et al., 2011; Resurreccion et al., 2012), as well as the algae-to-biofuel

53 conversion method (López Barreiro et al., 2013; Ríos et al., 2013; Torres et al., 2013).

The cost-competitiveness of a given pathway is, however, impacted by both

55 technical advances (i.e. decreasing capital and operating expenses) and project financing

56 assumptions, though only recently has uncertainty in the financial factors embedded in

57 economic analyses been addressed (Beal et al., 2015; Gerber et al., 2016; Resurreccion et

58 al., 2012; Richardson et al., 2012; Rogers et al., 2014; Stephens et al., 2010). Often, these

59 factors are not only uncertain but affected by facility design and the site-specific financing

60 environment. The technological readiness level (TRL), a measure of the maturity of a

61 production pathway, increases as a process advances from concept to the commercial scale

62 level (Mankins, 2009); higher TRL increases confidence in facility performance. This

63 confidence is in turn felt by investors, reducing their perceived risk of investment in the 
64 facility and thereby the return they require on construction capital. While advanced

65 techniques may therefore provide many advantages (e.g., reduced environmental impact,

66 energy demand, and capital and operating expenses), these must be weighed against the

67 increase in financing costs resulting from their incorporation. Environmental impacts,

68 dependent on the operating environment and production pathway techniques, also have the

69 potential to significantly impact economic competitiveness by determining whether a

70 facility qualifies for substantial performance-based subsidies (Resurreccion et al., 2012).

71 This work seeks to address previously unexplored interactions between technical

72 advances and financing parameters, and examine how tradeoffs resulting from these

73 interactions affect the cost competitiveness of optimal facility design. A TEA/LCA model

74 has been developed to evaluate performance benefits arising from the use of novel

75 techniques for (1) boosting lipid productivity with a bicarbonate amendment (Gardner et

76 al., 2013; Lohman et al., 2015) and (2) lowering capital costs and energy inputs for

77 dewatering by utilizing temperature-sensitive "hydrogels."(Vadlamani, 2014; Zhao, 2015)

78 These techniques are evaluated in pathways using either transesterification or hydrothermal

79 liquefaction (HTL) conversion techniques, and across a range of achievable algal lipid

80 content and growth rates, in order to assess the influence of these operational factors on the

81 relative benefits of novel technique incorporation.

82 The financing parameters embedded in the economic model are then varied to

83 evaluate the impact of accelerated depreciation methods, production tax credits, federal

84 loan guarantees, and a range of investment risk on these pathways. Variations from the

85 base financing assumptions allow a comparison of the relative economic competitiveness

86 improvements achievable from regulatory subsidies and how they vary based on the capital 
87 intensity of the processing pathway. Each technical and financial alternative is then

88 modeled in combination to identify maximally cost-competitive production pathways in

89 various plausible financing scenarios. Novel technology evaluation in this manner provides

90 a means for identifying the conditions, both operational (e.g., achievable algal lipid

91 production rate, conversion method) and financial (e.g., reduced interest rates and tax

92 liability) in which proposed production pathways are most economically competitive.

93 2. Methods

94 Simultaneous evaluation of environmental, economic, and energetic metrics for

95 algal biofuel production pathways composed of alternative sub-processes allows system

96 designers to select pathways that increase aggregate life cycle benefits (Delrue et al., 2012).

97 The methodology for performing LCA is well established (ISO 14040, 1997) and provides

98 a useful framework for an integrated and dynamic techno-economic and environmental

99 analysis of novel techniques (Figure 1).

$100 \quad 2.1$ Scope and Goal Definition

101 A systems model has been developed to examine the performance of an algal

102 biorefinery producing a "functional unit" of 10 million gallons of biofuel (either biodiesel

103 or renewable diesel) annually. The system boundary includes biofuels combustion (i.e. a

104 "well-to-wheels" scope) to facilitate comparisons with conventional fuel life cycles,

105 highlighting systems-level tradeoffs resulting from process-level decisions (Decicco, 2014).

106 Environmental impact analysis has, similar to previous analyses (Bennion et al.,

107 2015; van Boxtel et al., 2015), focused on the characterization of biorefinery global

108 warming potential (GWP) and energy balance in a "partial LCA" as designated by

109 international standards (ILCD, 2012). The energy and emissions associated with system 
110 construction are excluded, assumed to be similar for all the considered pathways and

111 relatively small when evaluated over the facility lifetime (Frank et al., 2011). The benefits

112 of an increasingly closed-loop production system (e.g. efficiently recycling material and

113 energy inputs as well as reducing emissions) are weighed against the increased capital

114 expense required to achieve this state.

115 The cumulative energy ratio (CER), calculated as the sum of direct energy inputs

116 and embodied energy (i.e. primary energy required to produce materials, thermal and

117 electric energy) of inputs and divided by the output fuel energy is used as the primary

118 energetic measure of the biofuel pathways (Collet et al., 2013). Using the methodology of

119 Hill et al. (2006), biofuels produced are assumed to displace fossil fuels based on the

120 pathway CER; a credit for avoided fossil emissions is subtracted from direct emissions

121 from the biofuel production pathway. Life cycle petroleum diesel fuel emissions (i.e.

122 including combustion) are multiplied by biorefinery CER to determine avoided emissions;

123 summing with pathway emissions and further dividing by diesel emissions calculates the

124 relative GWP of produced biofuels (Equation 1). Since the $\mathrm{CO}_{2}$ supplied to supplement

125 algae growth is assumed captured from industrial flue gas (at significant energy expense),

126 biofuel combustion is "carbon neutral," as emitted $\mathrm{CO}_{2}$ was recovered from an atmospheric

127 waste stream (Liu et al., 2013). The emissions and energy associated with process inputs

128 are obtained from GREET (GREET, 2011), other analyses, and industrial sources (see SI).

$G W P[\%$ of Diesel $]=\frac{\text { Diesel Emissions }\left[\frac{g \mathrm{CO}_{2} e q}{M J}\right] \times\left(1-\frac{\text { Energy Out }}{\text { Energy In }}\right)+\text { Pathway Emissions }\left[\frac{g \mathrm{CO}_{2} e q}{\mathrm{MJ}}\right]}{\text { Diesel Emissions }\left[\frac{g \mathrm{CO}_{2} e q}{M J}\right]}$

The minimum fuel selling price (MFSP) represents the breakeven selling price of

131 each gallon of biofuel produced, such that the net present value of the facility equals zero 
132 (i.e. Present Value of Costs $=$ Present Value of Revenues). This metric is calculated by

133 summing manufacturing and financing costs over the plant's lifetime and dividing by the

134 total volume of biofuel produced. In order to compare fuels of different energy contents,

135 MFSP is converted to dollars per gallon gasoline (energy) equivalent ( $\$$ gge $^{-1}$ ) by

136 multiplying by the ratio of gasoline energy content to biofuel energy content.

1372.2 Inventory and Impact Assessment

138 The algal biomass-to-biofuel pathway consists of four general stages: algae

139 cultivation, harvesting and dewatering, conversion to fuels, and recycling of nutrients and

140 energy. A baseline pathway, composed of commercially viable unit operations, was

141 initially developed and used to evaluate relative performance benefits achieved via

142 incorporation of novel techniques. Details of the conventional processes included in

143 baseline pathways are provided in the SI.

$144 \quad 2.3$ Novel Techniques

$145 \quad$ 2.3.1 Bicarbonate-Induced Lipid Productivity Boost

146 Efforts to boost oil production from algae have largely focused on nutrient stressing,

147 as nitrogen depletion can halt cell growth and induce energy storage via accumulation of

148 lipids (Sheehan et al., 1998). However, boosting lipid content at the expense of growth rate

149 can actually decrease the total lipid productivity (grams lipid produced $\mathrm{m}^{-2} \mathrm{~d}^{-1}$ ) and thereby

150 the biofuel production potential, making this tradeoff undesirable (Quinn and Davis, 2014).

151 Alternatively, recent work has shown that gains in total lipid productivity can be

152 achieved through controlled additions of sodium bicarbonate (Gardner et al., 2011, 2012,

153 2013). Low-grade sodium bicarbonate additions during growth increases the rate of

154 dissolved inorganic carbon uptake (Markou et al., 2014), boosting the specific growth rate 
155 by up to $69 \%$ and leading to an increase in overall biomass productivity of $27 \%$ (Lohman et

156 al., 2015). A second, higher concentration addition of $\mathrm{NaHCO}_{3}$ occurs as nitrogen is

157 depleted, inducing further lipid accumulation to increase the achievable biodiesel content

158 by $8 \%$. Together with the increased biomass productivity, total lipid productivity can be

159 increased $37 \%$ over that achievable by conventional growth techniques (see SI). Unlike the

160 biogenic $\mathrm{CO}_{2}$ recovered from flue gas, sodium bicarbonate represents a source of

161 sequestered carbon, and thus combustion of biofuel from algae grown with this inorganic

162 carbon addition incurs a corresponding GWP penalty.

$163 \quad 2.3 .2 \quad$ Hydrogel Dewatering

164 Hydrogels synthesized to respond to temperature changes by rapidly absorbing or

165 releasing water have been tested as an algal dewatering technique (Vadlamani, 2014) and

166 proven capable of concentrating algal slurries from $0.1 \mathrm{wt} \%$ up to $10 \mathrm{wt} \%$ with less than

$1671 \%$ biomass loss (Zhao, 2015). Fairly dilute algal cultures flow to a tank containing the

168 "hydrogels" where swelling occurs at room temperature; the algae-hydrogel mixture is then

169 passed through a sieve, where swollen gels are trapped and sent to a de-swelling tank in

170 which a $10^{\circ} \mathrm{C}$ temperature increase causes the gels to shrink (see SI for schematic). Given

171 that this temperature shift can occur between $32^{\circ} \mathrm{C}$ and $35^{\circ} \mathrm{C}$, waste heat captured via heat

172 exchangers is utilized to reduce de-swelling energy demands (Zhao, 2015).

1732.4 Growth Scenarios

174 Widely disparate values for achievable algal growth rates and lipid content are

175 reported in the literature and known to significantly affect predictions of biorefinery

176 performance (Collet et al., 2013; Quinn and Davis, 2014). Lipid productivity affects the

177 modeled performance of sub-process alternatives, impacting the choice of optimal growth 
178 reactor type (Richardson et al., 2014) and conversion method (Clarens et al., 2011). The

179 impact of incorporating a bicarbonate-induced lipid productivity boosts and hydrogel

180 dewatering in production pathways is therefore evaluated under two growth scenarios.

181 The "Ave. Growth" scenario is defined by the national average areal productivity

182 for open pond systems, calculated as $13.2 \mathrm{~g} \mathrm{~m}^{-2}$ day $^{-1}$ (Davis et al., 2012), and an average

183 extractable lipid content of $25 \%$ of dry algae by weight (henceforth referred to as wt $\%$ ). In

184 regions with higher insolation and less annual temperature variation, areal productivity can

185 be significantly greater, with various analyses showing growth rates of up to $40.6 \mathrm{~g} \mathrm{~m}^{-2} \mathrm{~d}^{-1}$

186 (Clarens et al., 2010). Additionally, species selection for biofuels production has shown

187 that certain algae are capable of accumulating up to 50wt\% lipids (Collet et al., 2013). A

188 "High Growth" scenario is therefore developed with an areal productivity of $32 \mathrm{~g} \mathrm{~m}^{-2} \mathrm{~d}^{-1}$

189 and a lipid content of $45 \mathrm{wt} \%$. To reflect the increased insolation and reduced temperature

190 variability, the average ambient temperature in this scenario is increased from $23^{\circ} \mathrm{C}$

191 (assumed for the "Ave. Growth" scenario) to $28^{\circ} \mathrm{C}$ (reflective of conditions in the US Gulf

192 Coast, Central America, the Middle East, and Southeast Asia). A selection of key model

193 inputs are presented in Table 1; the full list of modeling parameters is provided in the SI.

$194 \quad 2.5$ Financing Parameters

195 Financial assumptions embedded in feasibility analyses represent a significant

196 source of uncertainty (Quinn and Davis, 2014), with parameters affected by external market

197 conditions as well as linked to regulatory policies and facility design/operation (Gerber et

198 al., 2016). The maturity of a facility’s technology, as typified by the technology readiness

199 level (TRL), affects the perceived investment risk of the facility, which impacts the interest

200 rate for debt financing (Mankins, 2009). Choosing higher TRL pathways or employing 
managerial strategies to mitigate exposure to market, technology, and operational risks decreases overall investment risk, thereby reducing financing costs (Lamers et al., 2015).

204 technologies, federal loan guarantees, such as those offered by the Department of Energy

205 for advanced biofuel producers (Yacobucci, 2011), accelerate innovative technology

206 development and deployment by allowing low-TRL facilities access to lower-cost capital.

207 As per Jones et al. (2014), the facility is here is assumed to be financed 60\% with debt (the 208 other $40 \%$ from equity), with the MFSP calculated under three financing scenarios. The 209 baseline financing scenario assumes an interest rate (IR) of 8\%; an IR of 6\% represents a 210 "mitigated risk" scenario, wherein higher TRL or managerial actions reduce risk exposure; 211 and an IR of $4 \%$ represents a case in which the facility qualifies for a DOE Loan Guarantee.

212 The depreciation method used for the MFSP calculation is impacted by regulatory

213 policies designed to support renewable fuels. The depreciation charge is used to account 214 for the loss in value of capital assets over time, and is a percent of total capital expenses 215 that is deducted from the firm's taxable income (IRS, 2015). Straight line depreciation, 216 used for the baseline financial analysis, is calculated by dividing the total depreciable 217 capital expenses by the asset lifetime, such that an equal charge is applied annually until the 218 end of its useful life, at which point it is considered valueless. Accelerated depreciation 219 methods allow larger taxable income deductions early in the life of certain types of assets 220 (e.g., biofuels production equipment); using a standard discount rate to account for the time 221 value of money, the ability to defer tax liability to later in a facility's operational life 222 increases a project's present value (US PREF, 2014). The 7-yr Modified Accelerated Cost 223 Recovery System (MACRS) depreciation and Bonus depreciation, respectively currently 
224 and previously allowed for advanced biofuel facilities (Mendelsohn, 2012) methods can

225 provide a significant subsidy to such facilities (see SI). These accelerated depreciation

226 methods have been substituted for the straight line method to evaluate the impact on MFSP

227 calculations for all production pathways and growth scenarios.

228 The updated Renewable Fuel Standard sets minimum volumes of biofuels which

229 must be blended by refineries, supporting both biofuel demand and market value

230 (Yacobucci, 2011), thereby helping producers mitigate offtake risk and secure financing

231 (Miller et al., 2013). This policy further established a $\$ 1.01 \mathrm{gal}^{-1}$ production tax credit

232 (PTC) for biomass-based diesel fuel with life cycle GWP less than 50\% that of petroleum

233 diesel (enacted in 2007 and sporadically extended since (Yacobucci, 2011)). Evaluating

234 production pathways in an integrated LCA/TEA highlights how pathway design decisions

235 affect a facility's environmental performance, which determines eligibility for performance

236 based incentives, which affect the economic competitiveness of facility outputs. The

237 relative benefits of these financing improvements (i.e. interest rate reductions, accelerated

238 depreciation methods, and the PTC) are then compared for each proposed production

239 scenario, to examine interactions between pathway design and subsidy benefits.

$240 \quad 2.6$ Economic Assumptions

241 Equipment costs have been calculated using CapCost $^{\mathrm{TM}}$ (Turton et al., 2008) or

242 scaled from published analyses; details of technical operations, capital and operating

243 expenses for production pathway equipment are included in the SI. Recent design reports

244 have outlined economically competitive HTL production pathways for producing

245 renewable fuels from either whole-cell (Jones et al., 2014) or lipid extracted algae (Davis et

246 al., 2014); capital costs for the HTL pathway have been scaled from these reports. The 
247 methodology of these reports was further utilized for calculating initial and non-equipment

248 operating expenses; these factors, as well as the baseline parameters used for the MFSP

249 calculation, are outlined in the SI.

$250 \quad 2.7$ Interpretation

251 Transesterification produces biodiesel, lipid extracted algae (LEA), and glycerol in

252 proportions based on the algal cellular composition. LEA is utilized onsite via anaerobic

253 digestion (AD), where organic matter is converted to biogas and nutrients (primarily

254 nitrogen and phosphorous) are recoverable from the aqueous phase. Catalytic hydrothermal

255 gasification (CHG) of the nutrient-rich aqueous phase from HTL reactions reduces nitrogen

256 to ammonia and produces biogas from aqueous carbon (Liu et al., 2013). Nutrients

257 recovered from $\mathrm{AD}$ and $\mathrm{CHG}$ are recycled within the biorefinery to reduce net fertilizer

258 demands; biogas is sent to a combined heat and power system to reduce natural gas and

259 electricity inputs.

260 Any coproducts generated by the system that are not recycled within the facility

261 displace conventionally produced goods, with the emissions avoided from displaced

262 production processes credited to the facility (Chowdhury et al., 2012). Rather than

263 considering the uncertainties surrounding on-site uses for glycerol, this coproduct of the

264 transesterification reaction is substituted for biomass co-fired for bioelectricity offsite,

265 generating a credit based on its energetic content (Koutinas et al., 2014; Ponnusamy et al.,

266 2014). Integrating recycling processes has the potential to provide economic,

267 environmental, and energetic benefits to biorefineries by reducing external resource

268 demands. Assigning a credit to the avoided virgin resources effectively double-counts

269 these benefits when comparing different systems and was therefore avoided in this work. 
271 The nascent stage of the cultivation and conversion technology often necessitates

272 the use of data extrapolated from the bench scale for use in commercial scale feasibility

273 assessments, reducing certainty in modeled performance estimates (Collet et al., 2013).

274 While extrapolated data should be treated with caution, the National Algal Biofuels

275 Technology Roadmap (DOE, 2010) notes that qualitative trends emerging from modeling

276 efforts can be highly useful for guiding technical, economic and policy decisions. For

277 example, HTL modeling has been developed using processing parameters from Frank et al.

278 (2013) with hydrotreating parameters as well as capital and operating expenses scaled from

279 Jones et al. (2014) to match the functional unit of this analysis. Inclusion of this conversion

280 method is intended not to develop high resolution economic, energetic, or environmental

281 results, but rather to examine the potential differences in the impact of incorporating novel

282 sub-processes into pathways based around different conversion methods.

283 Exclusion of energy and emissions related to construction should be noted when

284 drawing comparisons with other energy production pathways, as this omission may assign

285 too little impact to algal biofuels (Clarens et al., 2010). The limited scope of environmental

286 impact assessment, while appropriate for the goals of this analysis, may also skew

287 comparisons with other fuel cycles. Comparing environmental impacts with terrestrial

288 biofuel production systems, which have considerable land use change, water use, and

289 eutrophication impacts (Clarens et al., 2011), would require further evaluation of algal

290 pathway performance in these impact categories.

291 3. Results

292 3.1 Pre-Screening and Analysis Overview 
Novel techniques (i.e. bicarbonate amendment and hydrogel dewatering) were

294 evaluated, separately as well as in combination, under both growth scenarios and with

295 cumulative changes to the financing parameters. Replacing conventional growth with

296 bicarbonate-induced lipid productivity boosting and dissolved air flotation with hydrogel

297 dewatering each separately yield economic, environmental, and energetic benefits. As the

298 benefits from incorporating these two novel techniques in tandem dominate those from

299 incorporation of either alone, results are presented for "Novel Tech." pathways which

300 include both the bicarbonate treatment as well as hydrogel dewatering. A summary of the

301 growth scenarios, processing advances, and financing parameters that make up the

302 examined production scenarios is provided in Table 2.

303 3.2 Novel Technique Incorporation

304 Pathways incorporating novel techniques are compared against conventional

305 operations under the average (“Ave. Growth”) and high (“High Growth”) achievable lipid

306 productivity growth scenarios and in pathways using either the transesterification or HTL

307 conversion process (Figure 2). In the Ave. Growth scenario, novel techniques reduce the

308 MFSP $22 \%$, the CER by $15 \%$, and GWP by $26 \%$ in the transesterification pathway,

309 compared to reductions of $19 \%, 10 \%$, and $18 \%$ (respectively) in HTL pathways. Though

310 unable to compete economically with HTL pathways in the Ave. Growth scenario, under

311 High Growth conditions the transesterification pathway with novel techniques has a lower

312 MFSP than the conventional HTL pathway, while also achieving a net energy output (0.93

313 kWh energy input per kWh energy output) and reducing GWP 22\% relative to petroleum

314 diesel. No pathway reaches the 50\% GWP reduction required to qualify for the PTC. 
Several trends are highlighted by the relative impacts of novel technique

316 incorporation under different operating scenarios (Table 3). The energetic, environmental,

317 and economic benefits of incorporating these novel techniques are greater in

318 transesterification than HTL-based pathways. Our model assumes that biocrude yield from

319 HTL is unaffected by cellular composition (see SI), while biodiesel yield from

320 transesterification is directly linked to lipid content (Frank et al., 2011). By increasing the

321 lipid productivity (grams lipid produced per $\mathrm{m}^{2}$ per day) above that otherwise achievable

322 (e.g., based on algal strain and growth conditions), bicarbonate additions increase the

323 biodiesel produced per gram of transesterified algae as well as the rate at which algae is

324 produced.

325 Combined with the decreased algae loss during processing with hydrogel

326 dewatering (2\% of throughput) relative to dissolved air flotation (10\%), these novel

327 techniques together significantly decrease the total algae required for the annual production

328 of $10 \mathrm{MM}$ gallons of biofuel. This in turn decreases the pond area required for the facility,

329 with a commensurate decrease in capital costs. However, novel technique incorporation

330 increases pathway capital intensity, the ratio of total capital investment to annual operating

331 costs, as greater initial expenses increase the efficiency of biofuel production and decrease

332 operating expenses. Further details regarding the performance benefits arising from novel

333 technique incorporation are available in the SI.

334 3.3 Combining Novel Techniques and Financing Improvements

335 Policy-derived incentives for investment (i.e. interest rate reductions, accelerated

336 depreciation of equipment) in biorefineries and production (i.e. tax credits) of biofuels are

337 evaluated to assess their impact on the economic competitiveness of the considered 
338 production pathways. As none of the pathways in either growth scenario qualify for the

339 federal production tax credit (PTC), only investment incentives impact economic

340 competitiveness. The relative impacts of novel technique incorporation, higher achievable

341 lipid productivity, and cumulative improvements from base financing assumptions for

342 transesterification and HTL pathways are illustrated in Figure 3.

343 Relative reductions in MFSP, CER, and GWP from novel technique incorporation

344 and operating under "High Growth" conditions are far greater for transesterification than

345 HTL-based pathways. Conversely, interest rate reductions and the availability of MACRS

346 depreciation allowances offer greater MFSP reductions for the more capital intensive HTL-

347 based pathways (Bonus depreciation offered no significant change in the MFSP for these

348 pathways and has therefore been omitted).

349 A strong positive correlation exists between the capital intensity ratio and the MFSP

350 reduction achieved via financing improvements, with these investment incentives offering

351 greater MFSP reductions to pathways with a greater fraction of costs from capital expenses

352 (Figure 4). Incorporating novel techniques increases the capital intensity, as does the use of

353 HTL, while capital expense reductions realized from operating under the "High Growth"

354 scenario decrease the capital intensity, with proportionate changes in MFSP reductions.

355 HTL-based systems are between 1.5 and 1.7 times more capital intensive than

356 transesterification-based pathways and realize MFSP reductions between $17 \%$ and $24 \%$

357 greater when investment incentives are available. This relationship follows from the way

358 these parameters affect facility financing: interest rate reductions decrease payments on

359 capital financed through debt, while accelerated depreciation allowances decrease taxable

360 income by a larger fraction of capital expenses early in the asset's life. Pathways with 
361 higher capital intensity will therefore achieve greater reductions in MFSP when these

362 financing improvements are available. This link between the capital intensity of a facility

363 and the economic benefit of regulatory financing improvements suggests that relevant, site-

364 specific policies need to be considered in the design of optimally competitive pathways.

365 3.4 Local Sensitivity Analysis

366 Increasing lipid content and biomass productivity via selection of optimal algal

367 strain and cultivation site has a greater impact on the performance of transesterification-

368 based pathways than on HTL-based pathways. Examining the performance impacts from

369 varying lipid content and productivities for transesterification pathways (Figure 5) shows

370 diminishing returns from increased productivity at higher lipid content. While HTL

371 pathway performance is unaffected by lipid content, low lipid content makes

372 transesterification less economically attractive at even the highest productivity levels. At

373 higher lipid content, transesterification pathways are able to compete economically with

374 HTL pathways, illustrating that site specific growth rates and achievable lipid content must

375 be considered carefully when designing production pathways.

376 The impact of single parameters embedded in the TEA/LCA model was analyzed by

377 varying inputs over a range encompassing literature estimates and evaluating the MFSP

378 sensitivity of transesterification and HTL-based production pathways (Figure 6). The

379 model is most sensitive to the specified discount rate for both conversion processes;

380 decreasing the discount rate to $8 \%$ induces a $2.5 \%$ and $3.3 \%$ reduction in transesterification

381 and HTL-based pathway MFSPs, respectively. After the discount rate, HTL-based systems

382 are next most sensitive to the capital expense of the conversion equipment, while variations

383 in transesterification reactor costs have a relatively smaller impact. The HTL pathway 
384 model is more sensitive than the transesterification model to annual operating days, capital

385 expenses for the autoflocculation tank and open raceway pond, and $\mathrm{CO}_{2}$ procurement costs.

386 Overall, the transesterification pathway is less sensitive to uncertainty in input

387 parameters. It should be noted that the algal lipid transesterification model has been adapted

388 from a standard model of commercial scale soy-oil transesterification (Frank et al., 2011)

389 while the HTL parameters are based on lab and pilot scale testing (Frank et al., 2013); such

390 extrapolation from a low TRL system may further increase HTL performance uncertainty.

3913.5 Perspectives

392 Several useful insights can be derived from this analysis. From a modeling

393 perspective, the finding that the benefits of novel techniques are closely linked to

394 operational assumptions infers that technique suitability analyses ought to be performed

395 across a range of plausible scenarios. From a financial perspective, results characterizing

396 the greater value of investment incentives to pathways with higher capital intensity suggest

397 these incentives are encouraging the development of facilities with greater upfront costs.

398 This artifact of the current policies should be given consideration as policymakers consider

399 how to effectively promote the development of liquid fossil fuel alternatives.

400 4. Conclusions

401 The novel techniques examined provide greater benefit to transesterification than

402 HTL-based production pathways. Investment incentives are more valuable to pathways

403 with a higher capital intensity, encouraging development of more efficient facilities with

404 greater upfront expenses when policies make such incentives available. Evaluation of

405 alternative techniques in a variety of operational and financing scenarios provides a more

406 accurate representation of the exact conditions in which sub-processes dominate 
407 alternatives, accelerating the development of energetically positive, environmentally

408 beneficial and economically competitive algal biorefineries. 


\section{ACKNOWLEDGEMENTS}

410 This work has benefitted greatly from close collaborations with researchers in the Center

411 for Biofilms Engineering at Montana State University and the Department of Chemical and

412 Environmental Engineering at The University of Toledo. The authors gratefully

413 acknowledge the research facilitation and feedback provided by Dr. Robin Gerlach, Dr.

414 Brent Peyton, Dr. Matthew Fields, Dr. Al Cunningham, and their respective research

415 groups at MSU. The researchers would like to thank the DOE (DE-EE0005993 / 000) and

416 NSF (SEP-1230710, 1230632, and 1230609) for their financial support of this research. 


\section{REFERENCES}

418 1. Beal, C.M., Gerber, L.N., Sills, D.L., Huntley, M.E., Machesky, S.C., Walsh, M.J., 419 Tester, J.W., Archibald, I., Granados, J., Greene, C.H., 2015. Algal biofuel production for fuels and feed in a 100-ha facility: A comprehensive techno-economic analysis and life cycle assessment. Algal Res. 10, 266-279. doi:10.1016/j.algal.2015.04.017

2. Bennion, E.P., Ginosar, D.M., Moses, J., Agblevor, F., Quinn, J.C., 2015. Lifecycle assessment of microalgae to biofuel : Comparison of thermochemical processing pathways q. Appl. Energy 1-10. doi:10.1016/j.apenergy.2014.12.009

3. Brennan, L., Owende, P., 2010. Biofuels from microalgae - A review of technologies for production, processing, and extractions of biofuels and co-products. Renew. Sustain. Energy Rev. 14, 557-577. doi:10.1016/j.rser.2009.10.009

4. Chisti, Y., 2007. Biodiesel from microalgae. Biotechnol. Adv. 25, 294-306. doi:10.1016/j.biotechadv.2007.02.001

5. Chowdhury, R., Viamajala, S., Gerlach, R., 2012. Reduction of environmental and energy footprint of microalgal biodiesel production through material and energy integration. Bioresour. Technol. 108, 102-11. doi:10.1016/j.biortech.2011.12.099

6. Clarens, A.F., Nassau, H., Resurreccion, E.P., White, M.A., Colosi, L.M., 2011. Environmental impacts of algae-derived biodiesel and bioelectricity for transportation. Environ. Sci. Technol. 45, 7554-7560. doi:10.1021/es200760n

7. Clarens, A.F., Resurreccion, E.P., White, M. a., Colosi, L.M., 2010. Environmental life cycle comparison of algae to other bioenergy feedstocks. Environ. Sci. Technol. 44, 1813-1819. doi:10.1021/es902838n

8. Collet, P., Spinelli, D., Lardon, L., Hélias, A., Steyer, J.-P., Bernard, O., 2013. LifeCycle Assessment of Microalgal-Based Biofuels. Biofuels from algae 287-312.

9. Davis, R., Fishman, D., Frank, E., Wigmosta, M., 2012. Renewable Diesel from Algal Lipids: An Integrated Baseline for Cost, Emissions, and Resource Potential from a Harmonized Model.

10. Davis, R., Kinchin, C., Markham, J., Tan, E., Laurens, L., Sexton, D., Knorr, D., Schoen, P., Lukas, J., 2014. Process Design and Economics for the Conversion of Algal Biomass to Biofuels : Algal Biomass Fractionation to Lipid- Products.

11. Decicco, J.M., 2014. The liquid carbon challenge: Evolving views on transportation fuels and climate. Wiley Interdiscip. Rev. Energy Environ. 4. doi:10.1002/wene.133

12. Delrue, F., Setier, P.-A., Sahut, C., Cournac, L., Roubaud, A., Peltier, G., Froment, A.K., 2012. An economic, sustainability, and energetic model of biodiesel production from microalgae. Bioresour. Technol. 111, 191-200. doi:10.1016/j.biortech.2012.02.020

13. DOE, 2010. National Algal Biofuels Technology Roadmap.

14. Frank, E., Han, J., Palou-Rivera, I., Elgowainy, A., Wang, M.Q., 2011. Life-Cycle Analysis of Algal Lipid Fuels with the GREET Model, Center for Transportation .... doi:ANL/ESD/11-5

15. Frank, E.D., Elgowainy, A., Han, J., Wang, Z., 2013. Life cycle comparison of hydrothermal liquefaction and lipid extraction pathways to renewable diesel from algae. Mitig. Adapt. Strateg. Glob. Chang. 18, 137-158. doi:10.1007/s11027-0129395-1 
16. Gardner, R., Peters, P., Peyton, B., Cooksey, K.E., 2011. Medium pH and nitrate concentration effects on accumulation of triacylglycerol in two members of the chlorophyta. J. Appl. Phycol. 23, 1005-1016. doi:10.1007/s 10811-010-9633-4

17. Gardner, R.D., Cooksey, K.E., Mus, F., Macur, R., Moll, K., Eustance, E., Carlson, R.P., Gerlach, R., Fields, M.W., Peyton, B.M., 2012. Use of sodium bicarbonate to stimulate triacylglycerol accumulation in the chlorophyte Scenedesmus sp. and the diatom Phaeodactylum tricornutum. J. Appl. Phycol. 24, 1311-1320. doi:10.1007/s10811-011-9782-0

18. Gardner, R.D., Lohman, E., Gerlach, R., Cooksey, K.E., Peyton, B.M., 2013. Comparison of $\mathrm{CO}(2)$ and bicarbonate as inorganic carbon sources for triacylglycerol and starch accumulation in Chlamydomonas reinhardtii. Biotechnol. Bioeng. 110, 8796. doi:10.1002/bit.24592

19. Gerber, L.N.H., Tester, J.W., Beal, C.M., Huntley, M., Sills, D., 2016. Target cultivation and financing parameters for sustainable production of fuel and feed from microalgae. Environ. Sci. Technol. acs.est.5b05381. doi:10.1021/acs.est.5b05381

20. GREET, 2011. GREET (The Greehhouse Gases, Regulated Emissions, and Energy Use in Transportation Model).

21. Hill, J., Nelson, E., Tilman, D., Polasky, S., Tiffany, D., 2006. Environmental, economic, and energetic costs and benefits of biodiesel and ethanol biofuels. Proc. Natl. Acad. Sci. U. S. A. 103, 11206-10. doi:10.1073/pnas.0604600103

22. ILCD, 2012. The International Reference Life Cycle Data System. doi:10.2788/85727

23. IPCC, 2007. International Panel on Climate Chance "AR4 Synthesis Report."

24. IRS, 2015. A Brief Overview of Depreciation [WWW Document]. URL http://www.irs.gov/Businesses/Small-Businesses-\&-Self-Employed/A-BriefOverview-of-Depreciation (accessed 3.5.15).

25. ISO 14040, 1997. Environmental management - Life Cycle Assessment - Principles and Framework.

26. Jones, S.B., Zhu, Y., Anderson, D., Elliott, D.C., Schmidt, A.J., Albrecht, K.O., Hart, T.R., Butcher, M., Drennan, C., Snowden-Swan, L., Davis, R., Kinchin, C., 2014. Process Design and Economics for the Conversion of Algal Biomass to Hydrocarbons : Whole Algae Hydrothermal Liquefaction and Upgrading.

27. Kirrolia, A., Bishnoi, N.R., Singh, R., 2013. Microalgae as a boon for sustainable energy production and its future research $\&$ development aspects. Renew. Sustain. Energy Rev. 20, 642-656. doi:10.1016/j.rser.2012.12.003

28. Klöpffer, W., 1997. Life cycle assessment: From the beginning to the current state. Environ. Sci. Pollut. Res. Int. 4, 223-228. doi:10.1007/BF02986351

29. Koutinas, A. a., Chatzifragkou, A., Kopsahelis, N., Papanikolaou, S., Kookos, I.K., 2014. Design and techno-economic evaluation of microbial oil production as a renewable resource for biodiesel and oleochemical production. Fuel 116, 566-577. doi:10.1016/j.fuel.2013.08.045

30. Lamers, P., Roni, M.S., Tumuluru, J.S., Jacobson, J.J., Cafferty, K., Hansen, J.K., Kenney, K., Teymouri, F., Bals, B., 2015. Techno-economic analysis of decentralized biomass processing depots. Bioresour. Technol. doi:10.1016/j.biortech.2015.07.009

31. Liu, X., Saydah, B., Eranki, P., Colosi, L.M., Greg Mitchell, B., Rhodes, J., Clarens, A.F., 2013. Pilot-scale data provide enhanced estimates of the life cycle energy and 
emissions profile of algae biofuels produced via hydrothermal liquefaction. Bioresour. Technol. 148, 163-171. doi:10.1016/j.biortech.2013.08.112

32. Lohman, E.J., Gardner, R.D., Pederson, T., Peyton, B.M., Cooksey, K.E., Gerlach, R., 2015. Optimized Inorganic Carbon Regime for Enhanced Growth and Lipid Accumulation in Chlorella vulgaris. Biotechnol. Biofuels 8, 1-13. doi:10.1186/s13068-015-0265-4

33. López Barreiro, D., Prins, W., Ronsse, F., Brilman, W., 2013. Hydrothermal liquefaction (HTL) of microalgae for biofuel production: State of the art review and future prospects. Biomass and Bioenergy 53, 113-127. doi:10.1016/j.biombioe.2012.12.029

34. Mankins, J.C., 2009. Technology readiness assessments: A retrospective. Acta Astronaut. 65, 1216-1223. doi:10.1016/j.actaastro.2009.03.058

35. Markou, G., Vandamme, D., Muylaert, K., 2014. Microalgal and cyanobacterial cultivation: The supply of nutrients. Water Res. 65, 186-202. doi:10.1016/j.watres.2014.07.025

36. Mendelsohn, M., 2012. § 1603 Treasury Grant Expiration : Industry Insight on Financing and Market Implications $§ 1603$ Treasury Grant Expiration : Industry Insight on Financing and Market Implications.

37. Miller, N., Christensen, A., Park, J.E., Barel, A., Seearle, S., 2013. Measuring and Addressing Investment Risk in the Second- Generation Biofuels Industry.

38. Ponnusamy, S., Kumar Reddy, H., Muppaneni, T., Meghan Downes, C., Shuguang Deng, and, 2014. Life cycle assessment of biodiesel production from algal bio-crude oils extracted under subcritical water conditions. Bioresour. Technol. doi:10.1016/j.biortech.2014.07.072

39. Quinn, J.C., Davis, R., 2014. The potentials and challenges of algae based biofuels: A review of the techno-economic, life cycle, and resource assessment modeling. Bioresour. Technol. doi:10.1016/j.biortech.2014.10.075

40. Rawat, I., Ranjith Kumar, R., Mutanda, T., Bux, F., 2013. Biodiesel from microalgae: A critical evaluation from laboratory to large scale production. Appl. Energy 103, 444467. doi:10.1016/j.apenergy.2012.10.004

41. Resurreccion, E.P., Colosi, L.M., White, M.A., Clarens, A.F., 2012. Comparison of algae cultivation methods for bioenergy production using a combined life cycle assessment and life cycle costing approach, in: Bioresource Technology. pp. 298-306. doi:10.1016/j.biortech.2012.09.038

42. Richardson, J.W., Johnson, M.D., Outlaw, J.L., 2012. Economic comparison of open pond raceways to photo bio-reactors for profitable production of algae for transportation fuels in the Southwest. Algal Res. 1, 93-100. doi:10.1016/j.algal.2012.04.001

43. Richardson, J.W., Johnson, M.D., Zhang, X., Zemke, P., Chen, W., Hu, Q., 2014. A financial assessment of two alternative cultivation systems and their contributions to algae biofuel economic viability. Algal Res. 4, 96-104. doi:10.1016/j.algal.2013.12.003

44. Ríos, S.D., Torres, C.M., Torras, C., Salvadó, J., Mateo-Sanz, J.M., Jiménez, L., 2013. Microalgae-based biodiesel: economic analysis of downstream process realistic scenarios. Bioresour. Technol. 136, 617-25. doi:10.1016/j.biortech.2013.03.046 
45. Rogers, J.N., Rosenberg, J.N., Guzman, B.J., Oh, V.H., Mimbela, L.E., Ghassemi, A., Betenbaugh, M.J., Oyler, G.A., Donohue, M.D., 2014. A critical analysis of paddlewheel-driven raceway ponds for algal biofuel production at commercial scales. Algal Res. 4, 76-88. doi:10.1016/j.algal.2013.11.007

46. Sheehan, J., Dunahay, T., Benemann, J., Roessler, P., 1998. Look Back at the U.S. Department of Energy's Aquatic Species Program: Biodiesel from Algae; Close-Out Report. doi:10.2172/15003040

47. Stephens, E., Ross, I.L., King, Z., Mussgnug, J.H., Kruse, O., Posten, C., Borowitzka, M. a, Hankamer, B., 2010. An economic and technical evaluation of microalgal biofuels. Nat. Biotechnol. 28, 126-8. doi:10.1038/nbt0210-126

48. Torres, C.M., Ríos, S.D., Torras, C., Salvadó, J., Mateo-Sanz, J.M., Jiménez, L., 2013. Microalgae-based biodiesel: a multicriteria analysis of the production process using realistic scenarios. Bioresour. Technol. 147, 7-16. doi:10.1016/j.biortech.2013.07.145

49. Turton, R., Bailie, R.C., Whiting, W.B., Shaeiwitz, J.A., 2008. Analysis, synthesis and design of chemical processes. Pearson Education.

50. US PREF, 2014. MACRS Depreciation and Renewable Energy Finance.

51. Vadlamani, A., 2014. Assessment of Temperature- and pH- Sensitive Hydrogels for Dewatering Dilute Algal Suspensions., in: AIChE Annual Meeting. Atlanta, GA.

52. van Boxtel, a. J.B., Perez-Lopez, P., Breitmayer, E., Slegers, P.M., 2015. The potential of optimized process design to advance LCA performance of algae production systems. Appl. Energy 154, 1122-1127. doi:10.1016/j.apenergy.2015.01.036

53. Yacobucci, B.D., 2011. Biofuels Incentives: A Summary of Federal Programs. Order Code RL33572 Washington, DC US Congr. Res. Serv.

54. Zhao, X., 2015. Harvesting Microalgae-Development of a Short Residence Time Method Using Rapid- response Temperature-sensitive Semi-IPN Hydrogels. University of Toledo.

55. Zhu, Y., Albrecht, K.O., Elliott, D.C., Hallen, R.T., Jones, S.B., 2013. Development of hydrothermal liquefaction and upgrading technologies for lipid-extracted algae conversion to liquid fuels. Algal Res. 2, 455-464. doi:10.1016/j.algal.2013.07.003 


\section{List of Tables}

582 Table 1. Select Model Parameters (capital and operating expenses adjusted to 2014 dollars)

583 Table 2. Growth scenarios, processing advances, and financing parameters composing

584 scenarios in which each production pathway is evaluated

585 Table 3. Changes in performance metrics and key operating parameters resulting from

586 incorporation of both bicarbonate triggers and hydrogel-based dewatering (i.e. novel

587 techniques)

588

$589 \quad$ List of Figures

590 Figure 1. Schematic of the integrated LCA/TEA modeling approach

591 Figure 2. Impacts from novel technique incorporation on minimum fuel selling price

592 (MFSP), cumulative energy ratio (CER), and global warming potential (GWP);

593 performance with conventional and novel growth and dewatering techniques are compared

594 under average and high growth (i.e. lipid productivity) scenarios for transesterification and

595 HTL-based pathways

596 Figure 3. Processing and financing improvements for transesterification and HTL-based

597 facilities; processing advances include incorporating both novel techniques and operating

598 under "High Growth" conditions; financing improvements include utilizing MACRS

599 accelerated depreciation allowances and iterative interest rate reductions

600 Figure 4. Process choices affect the capital intensity ratio (fixed capital investment/annual

601 operating expenses), which is correlated with the change in MFSP resulting from financing

602 improvements; this is shown for HTL (which have a higher capital intensity ratio) and

603 transesterification-based pathways as accelerated depreciation methods and lower interest

604 rates replace baseline financing assumptions

605 Figure 5. Sensitivity of transesterification and HTL pathways to biomass productivity

606 rates; transesterification-based pathways are evaluated across a range of achievable (i.e.

607 based on algal strain, not growth treatment) lipid contents; HTL performance is modeled as

608 independent of lipid content (see SI for details) Figure 6. MFSP sensitivity of

609 transesterification and HTL-based novel technique pathways in the "High Growth"

610 scenario; input ranges taken from literature (see SI) 
611 Table 1. Select Model Parameters (capital and operating expenses adjusted to 2014 dollars)

\begin{tabular}{|c|c|c|c|}
\hline Parameter & Value & Units & Reference \\
\hline \multicolumn{4}{|c|}{ Algae Cultivation } \\
\hline Land Cost & 3150 & \$/acre & Davis et al., 2011 \\
\hline Algal Productivity & 13.2 & $\mathrm{~g} / \mathrm{m}^{2} / \mathrm{d}$ & Davis et al., 2012 \\
\hline Operational Days & 330 & days/year & Davis et al., 2012 \\
\hline Lipid Content & $25 \%$ & & Davis et al., 2012 \\
\hline Pond Outlet Conc. & 0.5 & g DWB/L & Frank et al., 2011 \\
\hline Pond CapEx & $3.40 \mathrm{E}+04$ & $\$ /$ ha & $\begin{array}{l}\text { Lundquist et al. } \\
\text { (2010) }\end{array}$ \\
\hline Nitrogen Demand & 7.70E-02 & g N/g algae & Frank et al., 2011 \\
\hline Ammonia Cost & 427.35 & $\$ /$ ton $\mathrm{NH}_{3}$ & Davis et al., 2011 \\
\hline Phosphorous Demand & $8.10 \mathrm{E}-03$ & $\mathrm{~g} P / g$ algae & Frank et al., 2011 \\
\hline DAP Cost & 464.1 & $\$ /$ ton DAP & Davis et al., 2011 \\
\hline $\mathrm{CO}_{2}$ Cost & 42 & $\$ / \mathrm{kg}$ & Davis et al., 2011 \\
\hline \multicolumn{4}{|c|}{ Bicarbonate-Induced Lipid Productivity Boost } \\
\hline $\mathrm{HCO}_{3}$ Demand & 55 & $\mathrm{mM}$ & Gardner et al., 2013 \\
\hline $\mathrm{NaHCO}_{3} \mathrm{Cost}$ & 0.55 & $\$ / \mathrm{kg}$ & Industrial Quote \\
\hline \multicolumn{4}{|c|}{ Dewatering } \\
\hline Autofloc. CapEx & 82 & $\$ / \mathrm{m}^{3}$ & Delrue et al., 2012 \\
\hline DAF CapEx & $5.14 \mathrm{E}+06$ & $\$$ & $\begin{array}{l}\text { CapCost@ } \\
\text { Calculation }\end{array}$ \\
\hline \multicolumn{4}{|c|}{ Hydrogels } \\
\hline Temp Change & 10 & ${ }^{\circ} \mathrm{C}$ & Vadlamani, 2014 \\
\hline Retention Efficiency & $98 \%$ & & Vadlamani, 2014 \\
\hline Capex & $2.30 \mathrm{E}+06$ & $\$$ & $\begin{array}{l}\text { CapCost }{ }^{\circledR} \\
\text { Calculation }\end{array}$ \\
\hline OpEx & $4.61 \mathrm{E}+03$ & $\$$ & $\begin{array}{l}\text { CapCost@ } \\
\text { Calculation }\end{array}$ \\
\hline \multicolumn{4}{|c|}{ Dry Hexane Extraction } \\
\hline CapEx & 119 & \$/ton DWB & Chauvel et al., 2001 \\
\hline \multicolumn{4}{|c|}{ Transesterification } \\
\hline Capital Expense & 506.94 & $\$ /$ ton CL/yr & Chauvel et al., 2001 \\
\hline \multicolumn{4}{|c|}{ Hydrothermal Liquefaction } \\
\hline CapEx & $6.07 \mathrm{E}+07$ & $\$$ & Jones et al., 2014 \\
\hline \multicolumn{4}{|c|}{ Anaerobic Digestion } \\
\hline CapEx & 190 & $\$ /$ ton residue/yr & Davis et al., 2011 \\
\hline
\end{tabular}


613 Table 2. Growth scenarios, processing advances, and financing parameters composing 614 scenarios in which each production pathway is evaluated

\begin{tabular}{|c|c|c|}
\hline $\begin{array}{l}\text { Growth } \\
\text { Scenarios }\end{array}$ & $\begin{array}{l}\text { Average Growth } \\
\text { High Growth }\end{array}$ & $\begin{array}{l}13.2 \mathrm{~g} \mathrm{~m}^{-2} \mathrm{~d}^{-1} \text { Areal Productivity, } 25 \% \text { Lipid } \\
\text { Content } \\
32 \mathrm{~g} \mathrm{~m}^{-2} \mathrm{~d}^{-1} \text { Areal Productivity, } 45 \% \text { Lipid } \\
\text { Content }\end{array}$ \\
\hline $\begin{array}{l}\text { Processing } \\
\text { Pathways }\end{array}$ & $\begin{array}{l}\text { Conventional } \\
\text { Transesterification } \\
\text { Conventional } \\
\text { HTL } \\
\text { Novel Tech. }\end{array}$ & $\begin{array}{l}\text { Open raceway pond, autoflocculation, dissolved } \\
\text { air flotation, natural gas drum drying, hexane } \\
\text { extraction, transesterification, anaerobic digestion } \\
\text { of lipid extracted algae } \\
\text { HTL replaces transesterification; no natural gas } \\
\text { drum dryers are required; hydrotreating produces } \\
\text { renewable diesel from biocrude } \\
\text { Two-phase addition of } \mathrm{NaHCO}_{3} \text { during cultivation } \\
\text { to boost lipid productivity; Dissolved air flotation } \\
\text { is replaced by temperature sensitive hydrogels }\end{array}$ \\
\hline $\begin{array}{l}\text { Financing } \\
\text { Scenarios }\end{array}$ & $\begin{array}{l}\text { MACRS } \\
\text { Depreciation } \\
\text { Bonus } \\
\text { Depreciation } \\
\text { Production Tax } \\
\text { Credit (PTC) } \\
\\
6 \% \text { / 4\% Interest } \\
\text { Rate }\end{array}$ & $\begin{array}{l}\text { Straight line depreciation over } 12 \text { year recovery } \\
\text { period; } 40 \% \text { of capital financed through equity, } \\
\text { with debt repaid at } 8 \% \text { interest over } 10 \text { years } \\
\text { 7-year MACRS depreciation schedule replaces } \\
\text { straight line depreciation } \\
50 \% \text { of depreciable capital is deductible in the } \\
\text { first year of operations, followed by } 7 \text {-year } \\
\text { MACRS } \\
\text { Pathways with life cycle GWP }<50 \% \text { of } \\
\text { conventional diesel receive a } \$ 1.01 \text { gal }{ }^{-1} \text { tax credit, } \\
\text { which directly reduces the tax liability; deferred } \\
\text { tax assets accrue if credits are greater than current } \\
\text { liabilities } \\
\text { Interest rate reduction to } 6 \% \text { from } 8 \% \text {, represents } \\
\text { actions taken to mitigate project risks; reduction to } \\
4 \% \text { represents guarantee of project loans (e.g., } \\
\text { DOE Loan Guarantee) }\end{array}$ \\
\hline
\end{tabular}

615 
616 Table 3. Changes in performance metrics and key operating parameters resulting from

617 incorporation of both bicarbonate triggers and hydrogel-based dewatering (i.e. novel

618 techniques)

\begin{tabular}{c|cccc}
\multicolumn{2}{c}{} & \multicolumn{2}{c}{ TRANSESTERIFICATION } & \multicolumn{2}{c}{ HTL PATHWAYS } \\
\hline & Ave. Growth & High Growth & Ave. Growth & High Growth \\
\hline CER & $-15 \%$ & $-16 \%$ & $-10 \%$ & $-9 \%$ \\
GWP & $-23 \%$ & $-21 \%$ & $-18 \%$ & $-17 \%$ \\
ALGAE DEMAND & $-13 \%$ & $-16 \%$ & $-6 \%$ & $-6 \%$ \\
POND CAPEX & $-33 \%$ & $-33 \%$ & $-27 \%$ & $-25 \%$ \\
MFSP & $-22 \%$ & $-18 \%$ & $-19 \%$ & $-16 \%$ \\
\hline $\begin{array}{c}\text { CAPITAL INTENSITY } \\
\text { RATIO }\end{array}$ & $+4 \%$ & $+9 \%$ & $+14 \%$ & $+19 \%$ \\
\hline
\end{tabular}

619 
Figures

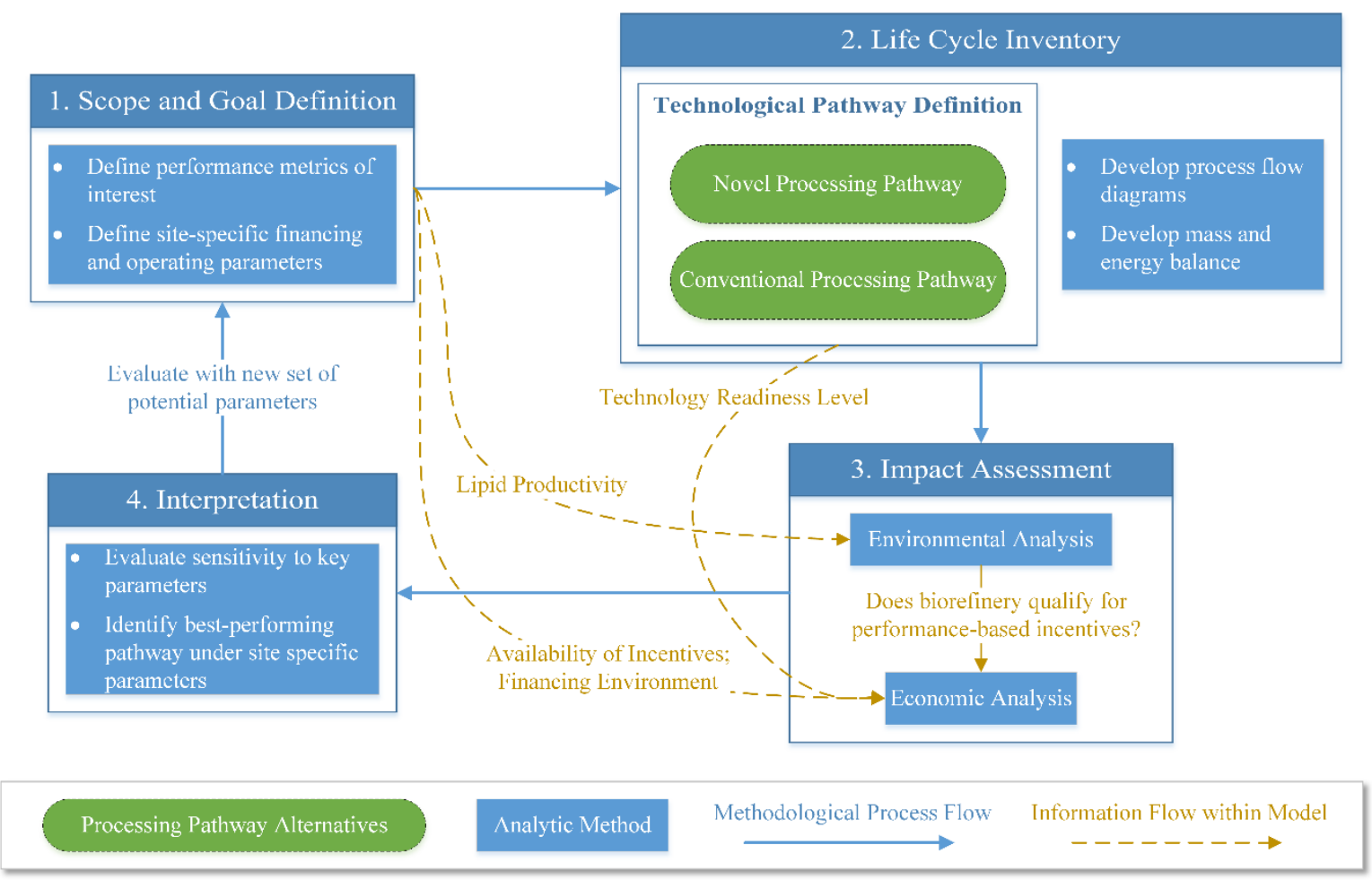




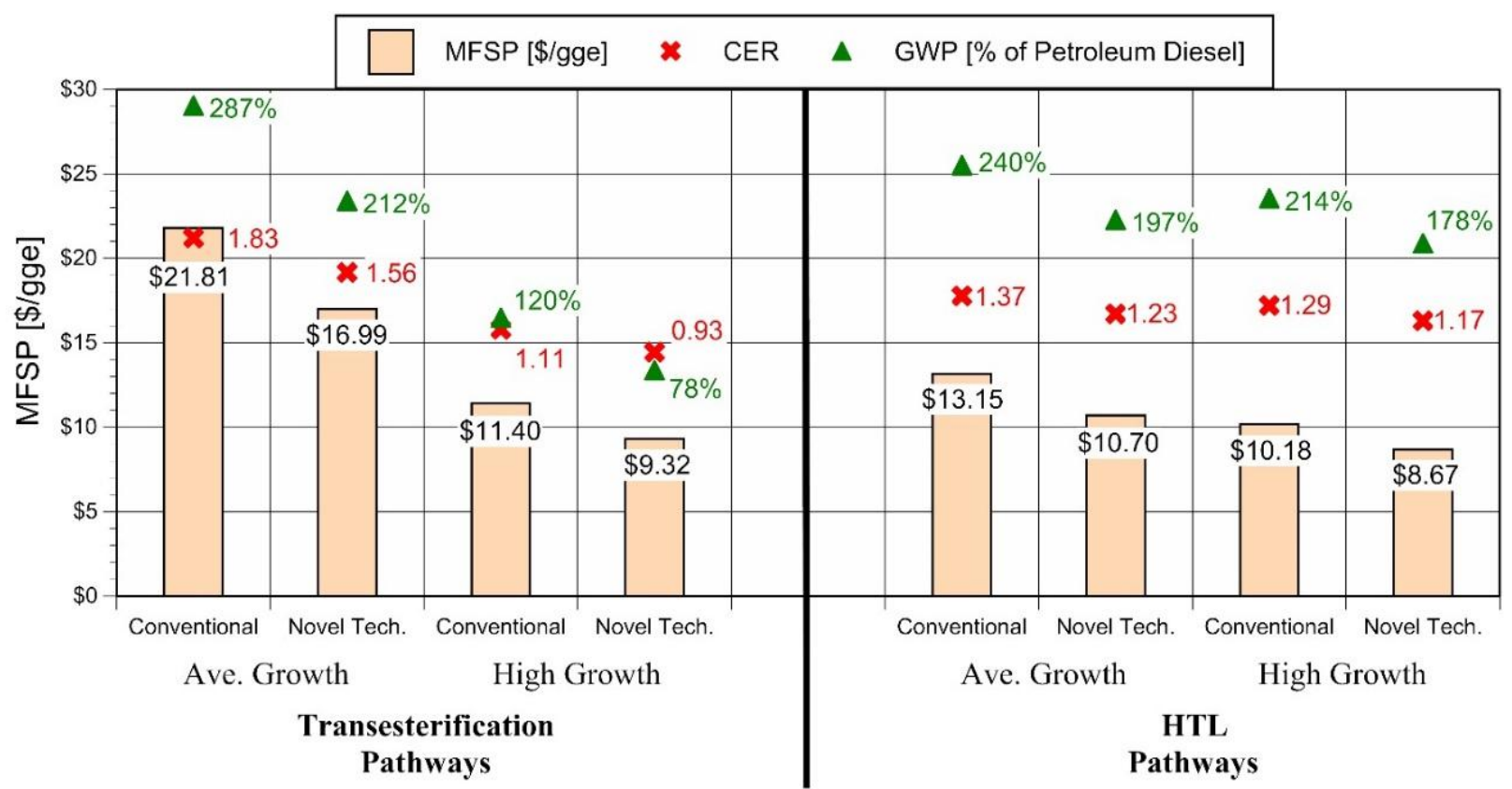

622 Figure 2. Impacts from novel technique incorporation on minimum fuel selling price 623 (MFSP), cumulative energy ratio (CER), and global warming potential (GWP);

624 performance with conventional and novel growth and dewatering techniques are compared 625 under average and high growth (i.e. lipid productivity) scenarios for transesterification and 626 HTL-based pathways 


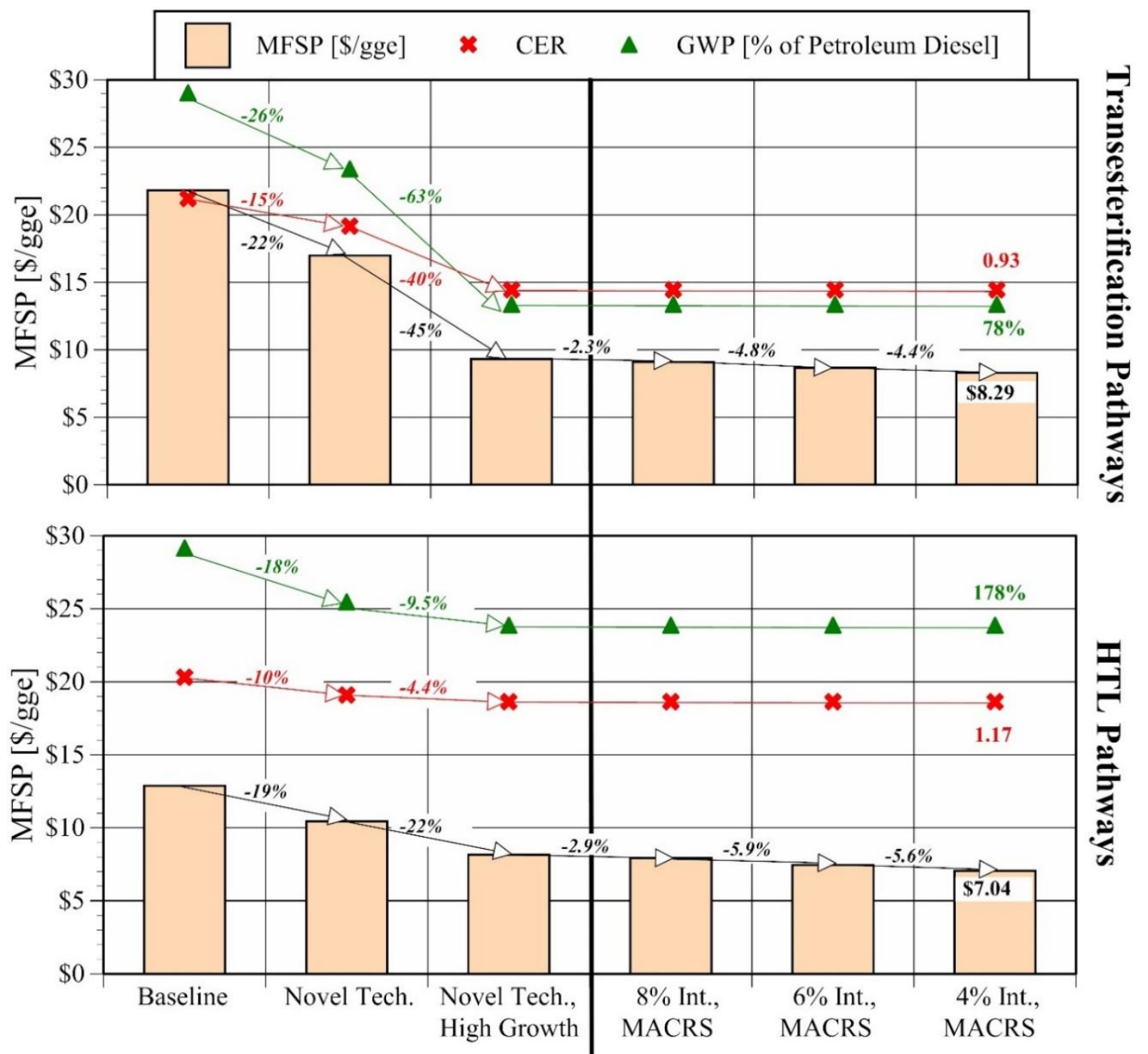

Processing Improvements

Financial Improvements

627 Figure 3. Processing and financing improvements for transesterification and HTL-based 628 facilities; processing advances include incorporating both novel techniques and operating 629 under "High Growth" conditions; financing improvements include utilizing MACRS 630 accelerated depreciation allowances and iterative interest rate reductions 


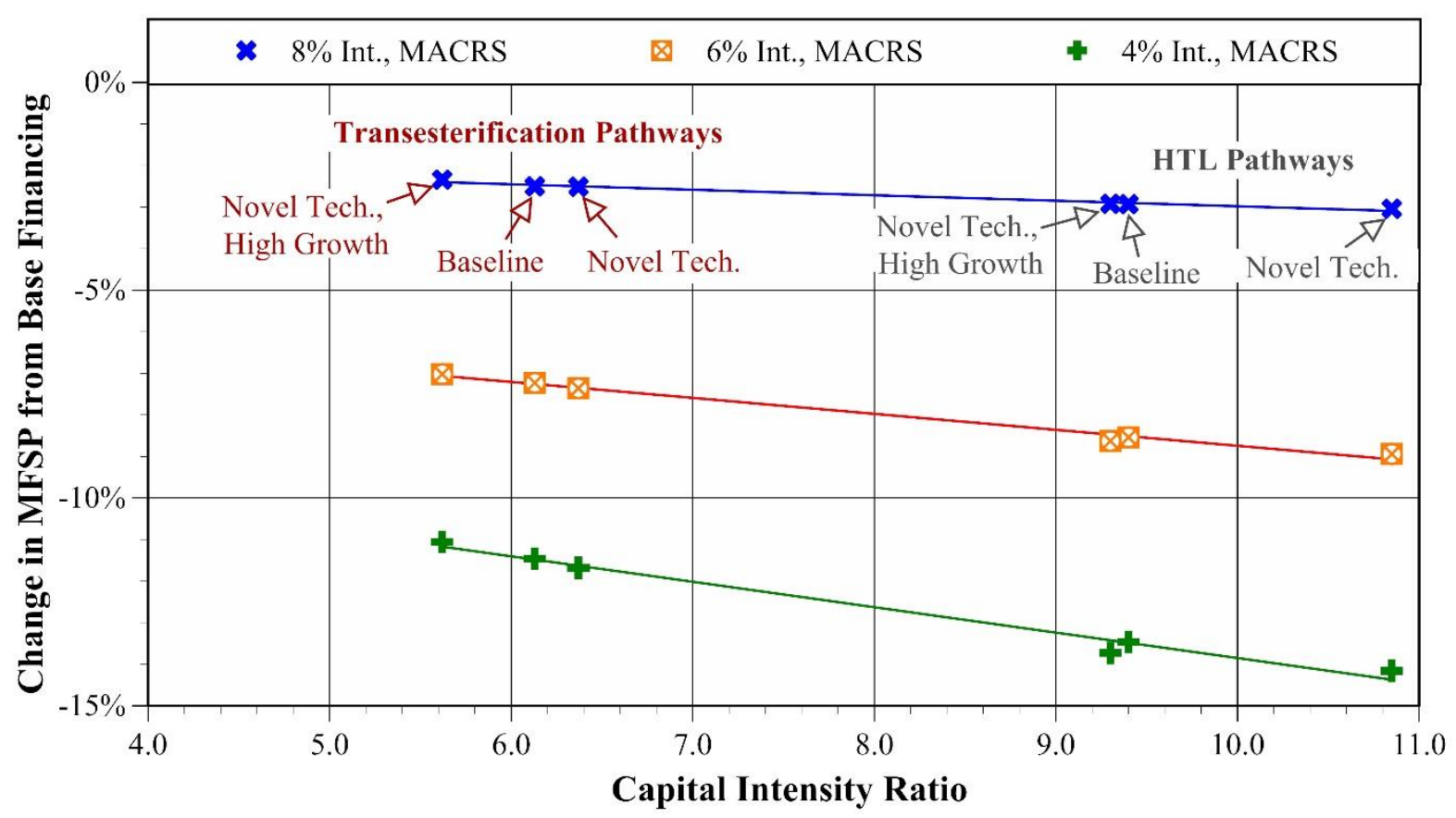

632 Figure 4. Process choices affect the capital intensity ratio (fixed capital investment/annual 633 operating expenses), which is correlated with the change in MFSP resulting from financing 634 improvements; this is shown for HTL (which have a higher capital intensity ratio) and 635 transesterification-based pathways as accelerated depreciation methods and lower interest 636 rates replace baseline financing assumptions 


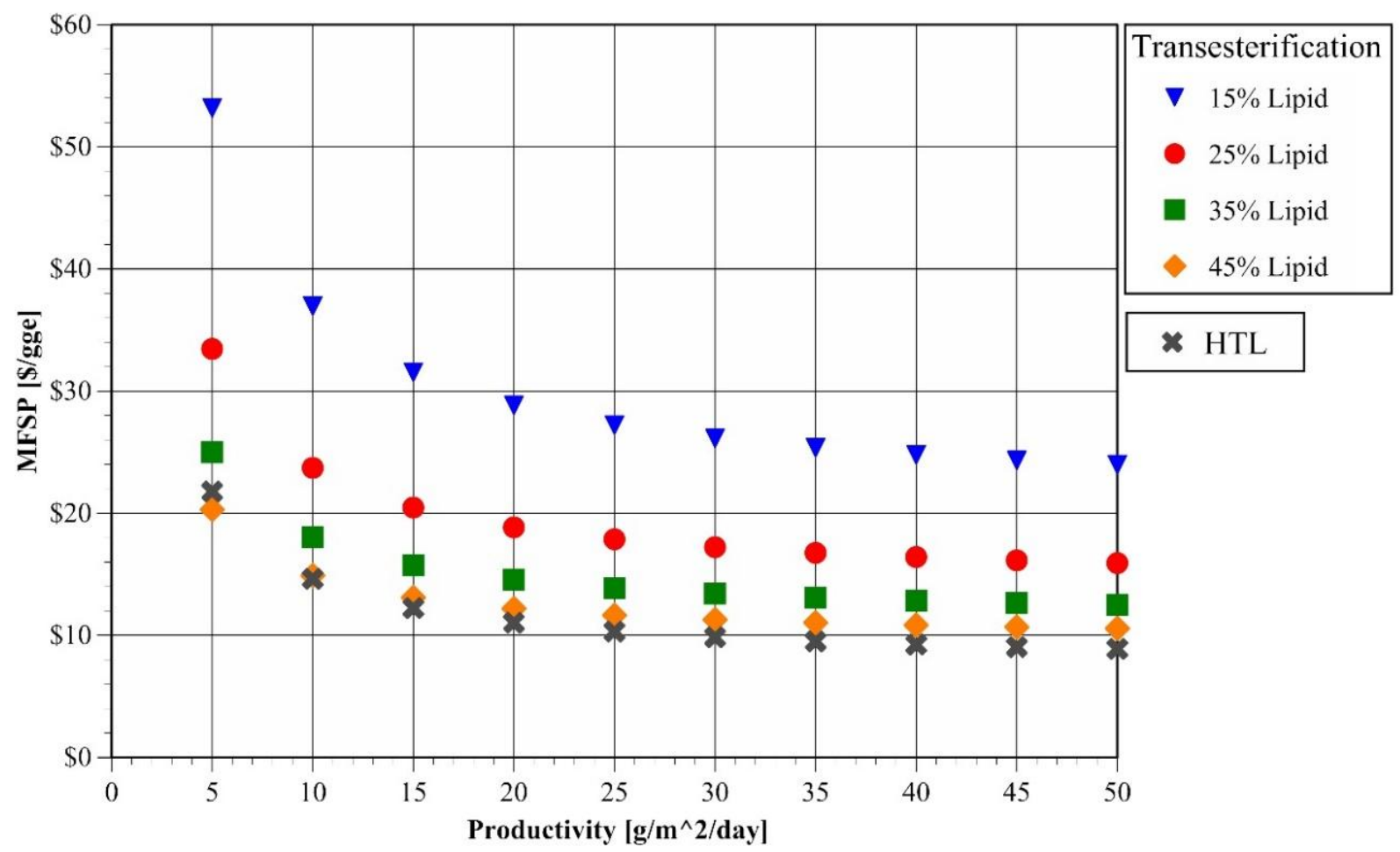

637 Figure 5. Sensitivity of transesterification and HTL pathways to biomass productivity 638 rates; transesterification-based pathways are evaluated across a range of achievable (i.e. 639 based on algal strain, not growth treatment) lipid contents; HTL performance is modeled as 640 independent of lipid content (see SI for details) 


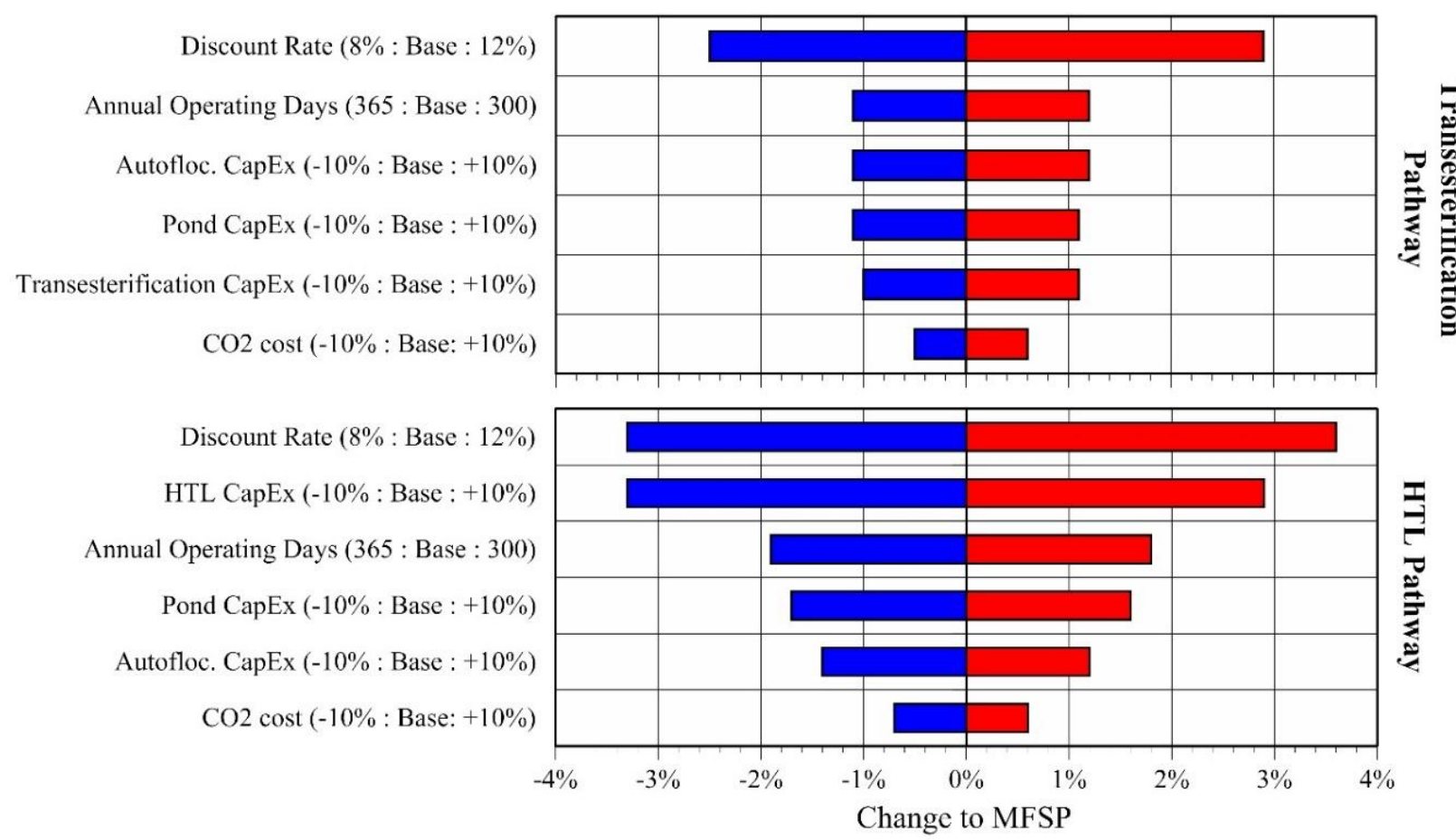

641 Figure 6. MFSP sensitivity of transesterification and HTL-based novel technique pathways 642 in the "High Growth" scenario; input ranges taken from literature (see SI) 